\title{
Recent research on the causes of Alzheimer's disease
}

\author{
BY M. J. ROWAN \\ Department of Pharmacology and Therapeutics, Trinity College, Dublin 2, Republic of Ireland
}

Alzheimer's disease (presenile and senile dementia of the Alzheimer type) is one of the most topical diseases of the late 20th century. This is not because it is a new disease but because senile dementia ('senility') has long been considered a normal part of ageing and has only recently (Blessed et al. 1968) been shown to be pathologically similar in the majority of cases to the young demented patients (presenile dementia) described by Alzheimer (1907) at the turn of the century.

Clinically, dementia is characterized by a gradual, often insidious, irreversible loss of intellectual/cognitive/social functioning which is not attributable to normal ageing or a change in the level of consciousness.

There are a number of different types of dementia with Alzheimer's disease being the most common, accounting for over $50 \%$ of cases either on its own or in combination with brain vascular disease (e.g. multi-infarct dementia, characterized by several ministrokes). Alzheimer's disease has been termed the 'hidden epidemic' because, relatively unnoticed, it has become one of the most serious medical and social problems facing the elderly and their carers. In mortality terms it is the fourth most common cause of death in the USA, affecting over three million Americans. In the UK approximately 350000 have the disease (Henderson, 1986) and in the Republic of Ireland there is an estimated 25000 sufferers (O'Neill et al. 1988).

Although ageing is not necessarily accompanied by serious cognitive decline there is a strong age-dependence of the disease. The prevalence of Alzheimer's disease increases exponentially as a function of age above the age of 65 years, with the occurrence of the disease being about one in five in those over 80 years of age (Royal College of Physicians, 1981). Since the population structure in developed countries is changing radically with the proportion of elderly greatly increasing, the projected number of those affected by the disease may double over the next $25-30$ years.

\section{SYMPTOMS AND CLINICAL DIAGNOSIS}

Since there are no treatments which successfully stop or prevent the disease, brain biopsy is not normally considered justified as a means of diagnosis. Clinicians are left with the difficult task of diagnosis by exclusion of other known causes of dementia. This is particularly difficult in the early stages of the disease. One of the first symptoms of the disease is the loss of memory for recent events and for names. Problems with driving, reading and socializing are common. As the disease progresses language and personality are major targets. Daily patterns of activity become simplified and the person is easily disoriented in place and time (e.g. wandering). The person can be under enormous personal stress and will often behave in a socially inappropriate manner (e.g. aggression). The final stages have been described as the 'living death' where the person becomes a shell of their former selves, having difficulty with the most basic aspects of living such as maintaining personal hygiene and feeding. The disease progresses over several years (usually 6-8 years from apparent onset) with the patient generally dying of 
a secondary illness (e.g. infections associated with long-term immobilization in bed). Since the patient becomes totally dependent an enormous burden is carried by the carers. They are under continual stress without appropriate community-oriented services, which are seldom available in most settings.

\section{POST-MORTEM NEUROPATHOLOGY}

Post-mortem confirmation of Alzheimer's disease is reasonably high (up to about $80-90 \%$ ) in cases which fulfil the National Institute of Neurology and Communicative Disorders and Stroke-Alzheimer's Disease and Related Disorders Association criteria for probable Alzheimer's disease (Joachim et al. 1988). The hallmark neuropathological features are senile (or neuritic) plaques and neurofibrillary tangles. Whereas the former have large extracellular cores of up to $200 \mu \mathrm{m}$ in diameter the latter are mainly found intracellularly, especially in pyramidal cells. Severe brain atrophy due to cell loss and shrinkage can be easily detected in the later stages of the disease but signs of neurodegeneration at the synaptic level where neuropil threads are found, occurs throughout the course of the disease.

There is evidence that neuropathological changes may precede the occurrence of easily recognizable clinical symptoms. One widely accepted system for staging the disease (Arnold et al. 1991; Braak \& Braak, 1991; Price et al. 1991) uses the neurofibrillary tangles and neuropil threads as markers. This method indicates that some of the earliest changes occur in the transentorhinal cortex, a region linking the temporal neocortex with the entorhinal region. With the appearance of clinical signs of impairment of cognition and slight personality changes the entire entorhinal cortex and related areas (thalamus, hippocampus and amygdala) become involved. Only later do neocortical association areas show marked changes at a stage when dementia is clearly present. The primary motor and sensory areas remain relatively unaffected. The proposed stages are consistent with the idea of the spread of the disease being a result of the connectivity rather than the proximity between cells.

It has been suggested that one of the reasons for the early involvement of memory changes is because the perforant path connecting the temporal cortex with the hippocampus is susceptible to damage in the entorhinal and transentorhinal areas (Hyman et al. 1986). There is also substantial evidence implicating destruction of the cholinergic neurones innervating forebrain regions as a major target in providing a basis for the cognitive decline. However, no one neurotransmitter or neurone appears to be the only primary target in the disease (Cowburn et al. 1989).

Although neuritic plaques can be observed in the neocortex at a time when there is little evidence of neurofibrillary changes in the brain there is no pattern of deposition that allows a clear staging of the disease (Braak \& Braak, 1991). Neither neuritic plaques nor neurofibrillary tangles are unique to Alzheimer's disease being present to varying degrees in normal ageing and other neurological diseases (e.g. post-encephalitic Parkinsonism).

\section{$\beta$-AMYLOID HYPOTHESIS}

Recent cellular and molecular studies have greatly advanced our understanding of the neuropathology of the disease, providing insights into possible mechanisms for its 
aetiology and pathogenesis (Goedert et al. 1991b; Hardy \& Allsop, 1991; Selkoe, 1991; Hardy \& Higgins, 1992; Marotta et al. 1992). The central core of senile plaques is composed mainly of highly insoluble $\beta$-pleated proteinaceous fibrils. These largely contain the thirty-nine to forty-two amino acid long $\beta$-amyloid (A4) peptide. Microglia are also observed in the centre of the plaques. Surrounding the core degenerating neurites (dendrites and axons) and reactive astrocytic cells are found. The discovery that diffuse deposits of $\beta$-amyloid are detectable in many brain regions in clinically unaffected individuals has led to the suggestion that these deposits are precursors of the senile plaques. However, the latter occur primarily in the neocortex and a few subcortical areas such as the hippocampus. Some factor or a lack of protection must make the cells in these areas more sensitive to the pathology. Heparin sulphate, other proteoglycans, inorganic elements and $\alpha_{1}$-antichymotrypsin have all been found closely associated with senile plaques.

The $\beta$-amyloid peptide has been found to be both neurotrophic and neurotoxic to cultured cells (Yankner et al. 1990; Hardy \& Higgins, 1992). Older cultured neurones or those exposed to excitatory amino acids acting at $\mathrm{N}$-methyl-D-aspartate receptors or nerve growth factor are particularly sensitive to the toxic effects. It would appear that the ability of the peptide to aggregate and form fibrils is critical (Pike et al. 1991). A critical role for $\beta$-amyloid-induced loss in the ability of cells to buffer changes in intracellular $\mathrm{Ca}$ has also been proposed. The neurotoxicity is shared by the $\beta$-amyloid $25-35$ fragment which contains a sequence homologous to substance $P$. Subsequently substance $P$ was found to protect against the toxicity. In vivo injection of $\beta$-amyloid into the frontal cortex of rats produced neurodegeneration (Kowall et al. 1991). This was also reduced by systemic administration of substance $P$. Interestingly the injection of the cores of senile plaques from Alzheimer's patients into rat brain is also neurotoxic (Frautsch et al. 1991), pointing to the possible involvement of immune mechanisms (e.g. complement-induced cytotoxicity). Neither of these in vivo models produced all the hallmarks of the disease seen in man. The fact that $\beta$-amyloid deposition in the neocortex of patients with frontal lobe dementia can occur without neuritic plaque formation may mean that other cofactors are involved.

The source of $\beta$-amyloid is now known to be $\beta$-amyloid precursor protein (APP). This protein has at least three isoforms which contain the $\beta$-amyloid sequence. They all have a membrane spanning part near the intracellular carboxyl-terminal. The $\beta$-amyloid sequence forms part of this transmembrane component (up to fourteen amino acids) and extends to include some (approximately twenty-eight) extracellular amino acids. Two isoforms contain a Kunitz-type serine protease inhibitor domain $\left(\mathrm{APP}_{751}\right.$ and $\left.\mathrm{APP}_{770}\right)$ whereas $\mathrm{APP}_{695}$ is the dominant form in the central nervous system.

It is still unclear exactly how $\beta$-amyloid is formed from APP. One of the major metabolic pathways (Younkin, 1991) for APP involves the cleavage of the molecule in the middle of the $\beta$-amyloid sequence (residues 15-17) by a 'secretase' enzyme which releases the large amino-terminal ecto-domain from the membrane. The resulting soluble APP include protease nexin-II. This is found especially in the $\alpha$-granules of platelets and is thought to have a role in coagulation and immunomodulation. Since these secreted forms of APP contain only a part of the $\beta$-amyloid sequence they, or the remaining membrane-bound fragments, cannot be the source of $\beta$-amyloid in Alzheimer's disease.

Recently an alternative pathway which involves the intracellular metabolism of APP in 
an endosomal-lysosomal compartment has been demonstrated (Golde et al. 1991; Estus et al. 1992). Various carboxyl-terminal fragments which appear to include the $\beta$-amyloid sequence have been detected. It still remains to be shown that these are further broken down to produce $\beta$-amyloid and the question of why the peptide is normally found extracellularly in Alzheimer's disease senile plaque cores remains unanswered. The problem of the relative contribution of neuronal/glial/vascular (e.g. brain capillary endothelial cells and circulating blood cells) tissue to the plaques is still subject to debate.

The discovery that there is a marked reduction in APP levels in the cerebrospinal fluid of Alzheimer's disease patients (Van Nostrand et al. 1992) lends strong support to the idea that abnormal APP metabolism is fundamental to the disease. The possibility that fragments other than $\beta$-amyloid may be neurotoxic or contribute to the overall progress of the disease is only beginning to be investigated.

\section{PAIRED HELICAL FILAMENTS}

Neurofibrillary tangles, neurites of senile plaques, and neuropil threads are composed of relatively insoluble (Goedert et al. 1991b; Wischik, 1991) paired helical filaments. These are normally formed in a double-helical stack of ' $\mathrm{C}$ '-shaped sub-units twisted into a ribbon-like structure crossing about every $80 \mathrm{~nm}$. The primary constituent of the protease-resistant core is believed to be a part of the microtubule-associated protein called tau. Tau from Alzheimer's disease brain is abnormally phosphorylated, consisting of three tau isoforms with molecular weights of 60,64 and $68 \mathrm{kD}$. These are tightly cross-linked at the repeat region of tau in paired helical filaments, thus preventing tau performing its normal functions of promoting the assembly and stabilization of microtubules (Goedert et al. 1991a). This leads to disturbed axoplasmic transport. Excessive amounts of the paired helical filaments will disrupt the normal cytoskeletal system with consequent destabilization of cellular function including cell connectivity and will often cause cell death. This leads to the eventual extracellular deposition of 'tombstone' tangles at the sites of neuronal destruction.

The origin of the over-production (or under-metabolism) of abnormally phosphorylated tau is unknown. Whether it is due to a change in protein kinases and/or phosphatases selectively affecting tau phosphorylation states or to some other factor that makes tau particularly susceptible to generalized changes in intracellular protein phosphorylation-dephosphorylation is not clear. Other molecules found associated with paired helical filaments, such as the protease ubiquitin, may play a crucial role. It has been suggested that $\beta$-amyloid-induced destabilization of intracellular Ca may be a link between the two major hallmarks of the disease (Hardy \& Higgins, 1992).

\section{GENETIC FACTORS}

Perhaps the strongest evidence for the role of APP and $\beta$-amyloid comes from genetic studies of a very small number of patients with the autosomal dominant familial form of the disease (Castano et al. 1991) and of Down's syndrome patients (Giaccone et al. 1989). In about ten families world-wide a missense mutation of the codon 717 occurs on the APP gene located on chromosome 21 . This results in the substitution of the native valine, located three residues away from the carboxy-terminal end of $\beta$-amyloid, with isoleucine, phenylalanine or glycine. Since this region normally forms part of the 
transmembrane spanning part of APP the report that this change can lead to the increased secretion of the intact molecule from cells (cultured fibroblasts from these patients) is of critical importance in our understanding of the sequence of events leading to the inevitable clinical symptoms (D. Goldgaber, unpublished results). Abnormal metabolism of APP as a likely cause of the pathology in these patients is supported by preliminary findings from studies of transfected cultured cells over-expressing the mutant forms of APP (B. A. Yankner, unpublished results). Activation of intracellular phosphorylation in these cells resulted in an increased and maintained release of carboxy-terminal fragments of APP which appeared to include the $\beta$-amyloid sequence.

Down's syndrome is caused by trisomy of chromosome 21 including the region that contains the APP gene. This will lead to a $50 \%$ increase in gene dosage which should produce an over-expression of APP. Nearly all these patients develop the neuropathological markers of Alzheimer's disease by the end of their fifth decade (Ellis et al. 1974). Most of the stages described previously for Alzheimer's disease are apparent at earlier ages in Down's syndrome (Giaccone et al. 1989; Hyman \& Mann, 1991). The fact that it still takes decades for the full pattern to emerge points to the potential difficulties in using the genetic over-expression approach to model the disease in animals. Only two animal models of genetic aspects of Alzheimer's disease have been accepted as verifiable. Brain tissues from transgenic mice which have been induced to over-produce $A P_{751}$ (Quon et al. 1991) or from transplants from mice with a genetic equivalent to trisomy 21 (Richards et al. 1991) show signs of neurodegeneration but only at a low level. None of the animal models show senile plaques and neurofibrillary tangles. This may be because insufficient time is available in mice for the disease to progress to the extent seen in humans.

Familial Alzheimer's disease is genetically heterogeneous, not being even restricted to changes in chromosome 21. These patients form a small proportion of cases of Alzheimer's disease with a marked tendency for early ( $<65$ years) onset. Although a positive family history is, apart from age, the major known risk factor it is impossible to definitely attribute this to a genetic as opposed to an environmental cause. The age of onset of clinical symptoms even for monozygotic twins varies markedly (Farrer et al. 1990). EURODEM Risk Factors Research Group (1991) showed that although there are significantly more late onset patients with positive family history of dementia than controls, the relative risk factor is significantly less than that for early onset. The problem of death of relatives from other causes makes these kinds of studies extremely difficult in an elderly population.

\section{ENVIRONMENTAL FACTORS: ALUMINIUM}

It is generally believed that the predominant, sporadic form of the disease is at least partly triggered by some environmental factors such as head injury (Royston et al. 1992) and possibly Al. However, the epidemiological findings are not consistent with any of these putative causes as being a major influence on its own.

Interest in the possibility that Al might play a role in Alzheimer's disease was instigated by the discovery that this potentially highly neurotoxic element (Van der Voet et al. 1991) produced neurofibrillary tangles in the cat and rabbit (e.g. Klatzo et al. 1965). It was subsequently found that these tangles were different from Alzheimer's disease tangles, being composed of phosphorylated straight neurofilaments. There is little doubt 
that relatively high sub-acute exposure to $\mathrm{Al}$ causes dialysis dementia which is characterized not only by cognitive changes but also speech disturbance, seizures and if unchecked, death within 1 year. Recent preliminary evidence from J. A. Edwardson and co-workers (Candy et al. 1992) indicates that even though the brains of non-demented renal dialysis patients do not show senile plaques or neurofibrillary tangles, there may be increased diffuse $\beta$-amyloid deposition in one-third of cases and raised levels of abnormal tau in brains with high $\mathrm{Al}$ levels.

The presence of $\mathrm{Al}$ in senile plaques or neurofibrillary tangles is controversial. This may be the result of the use of different techniques. Similarly the proposal that the metal chelator desferrioxamine (Crapper McLachlan et al. 1991) delays the progress of the disease is the subject of heated debate (Flaten et al. 1991). It is not known if systemic desferrioxamine is capable of removing Al from the brain.

A number of epidemiology studies point to a small but significant risk contribution to dementia of environmental exposure to $\mathrm{Al}$ or lack of protection by neutralizing agents such as fluoride or silicone (Editorial, 1992). Whether or not this relates to Alzheimer's disease directly or possibly indirectly by increasing the likelihood of dementing symptoms occurring is a matter of conjecture. Detailed discussion of the issues involved is provided by Walton (1991) and Williams (1992).

\section{REFERENCES}

Alzheimer, A. (1907). On a peculiar disease of the cerebral cortex. (Uber eine eigenartige Erkrankung der Hirnrinde.) Translation by R. H. Wilkins \& I. A. Brody (1969). Archives of Neurology 21, 109-110.

Arnold, S. E., Hyman, B. T., Flory, J., Damasio, A. R. \& van Hoesen, G. W. (1991). The topographical and neuroanatomical distribution of neurofibrillary tangles and neuritic plaques in the cerebral cortex of patients with Alzheimer's disease. Cerebral Cortex 1, 103-116.

Blessed, G., Tomlinson, B. E. \& Roth, M. (1968). The association between quantitative measures of dementia and of senile change in the cerebral grey matter of elderly subjects. British Journal of Psychiatry 114, 797-811.

Braak, H. \& Braak, E. (1991). Neuropathological stageing of Alzheimer-related changes. Acta Neuropathologica 82, 239-259.

Candy, J. M., McArthur, F. K., Oakley, A. E., Taylor, G. A., Chen, C. P. L.-H., Mountfort, S. A., Thompson, J. E., Chalker, P. R., Bishop, H. E., Beyreuther, K., Perry, G., Ward, M. K., Martyn, C. N. \& Edwardson, J. A. (1992). Aluminium accumulation in relation to senile plaque and neurofibrillary tangle formation in the brains of patients with renal failure. Journal of Neurological Sciences 107, 210-218.

Castano, E. M., Wisniewski, T. \& Frangione, B. (1991). Inherited amyloids of the nervous system. Current Opinion in Neurobiology 1, 448-454.

Cowburn, R. F., Hardy, J. A. \& Roberts, P. J. (1989). Neurotransmitter deficits in Alzheimer's disease. In Alzheimer's Disease: Towards an Understanding of the Aetiology and Pathogenesis, pp. 9-32 [D. C. Davies, editor]. London: John Libbey.

Crapper McLachlan, D. R., Dalton, A. J., Kruck, T. P. A., Bell, M. Y., Smith, W. L., Kalow, W. \& Andrews, D. F. (1991). Intramuscular desferrioxamine in patients with Alzheimer's disease. Lancet 337, $1304-1308$.

Editorial (1992). Is aluminium a dementing ion? Lancet 339, 713-714.

Ellis, W. G., McCulloch, I. R. \& Corley, C. L. (1974). Presenile dementia in Down's Syndrome. Ultrastructural identity with Alzheimer's Disease. Neurology 24, 101-106.

Estus, S., Golde, T. E., Kunishita, T., Blades, D., Lowery, D., Eisen, M., Usiak, M., Qu, X., Tabira, T., Greenberg, B. D. \& Younkin, S. G. (1992). Potentially amyloidogenic, carboxyl-terminal derivatives of the amyloid protein precursor. Science $255,726-728$.

EURODEM Risk Factors Research Group (1991). Risk Factors for Alzheimer's Disease: a Collaborative Re-analysis of Case-Control Studies. International Journal of Epidemiology 20, Suppl. 2.

Farrer, L. A., Meyers, R. H. \& Cupples, L. A. (1990). Transmission and age-at-onset patterns in familial Alzheimer's disease: Evidence of heterogeneity. Neurology 40, 395-403. 
Flaten, T. P., Garrutto, R. M. \& Davies, P. (1991). Desferrioxamine for Alzheimer's disease. Lancet 338, 324-326.

Frautsch, S. A., Baird, A. \& Cole, G. M. (1991). Proceedings of the National Academy of Sciences USA 88, 8362-8366.

Giaccone, G., Tagliavini, F. \& Linoli, G. (1989). Down patients: extracellular preamyloid deposits precede neuritic degeneration and senile plaques. Neuroscience Letters 97, 232-238.

Goedert, M., Crowther, R. A. \& Garner, C. C. (1991a). Molecular characterization of microtubule-associated proteins Tau and MAP2. Trends in Neuroscience 14, 193-199.

Goedert, M., Sisodia, S. S. \& Price, D. L. (1991b). Neurofibrillary tangles and $\beta$-amyloid deposits in Alzheimer's disease. Current Opinion in Neurobiology 1, 441-447.

Golde, T. E., Estus, S., Younkin, C. H., Delkoe, D. J. \& Youngin, S. G. (1992). Science 255, 728-730.

Hardy, J. \& Allsop, D. (1991). Amyloid deposition as the central event in the aetiology of Alzheimer's disease. Trends in Pharmacological Sciences 12, 383-388.

Hardy, J. A. \& Higgins, G. A. (1992). Alzheimer's disease: the amyloid cascade hypothesis. Science 256, 184-185.

Henderson, A. S. (1986). The epidemiology of Alzheimer's Disease. British Medical Bulletin 41, 3-10.

Hyman, B. T. \& Mann, D. M. A. (1991). Alzheimer-type pathological changes in Down's syndrome individuals of various ages. In Alzheimer's Disease: Basic Mechanisms, Diagnosis and Therapeutic Strategies, pp. 106-113 [K. Iqbal, D. R. C. McLachlan, B. Winblat and H. M. Wismewski, editors]. Chichester: John Wiley \& Sons.

Hyman, B. T., Van Hoesen, G. W., Kromer, I. J. \& Damasio, A. R. (1986). Perforant pathway changes and the memory impairment of Alzheimer's disease. Annals of Neurology 20, 472-481.

Joachim, C. L., Morris, J. H. \& Selkoe, D. J. (1988). Clinically diagnosed Alzheimer's disease: autopsy results in 150 cases. Annals of Neurology 24, 50-56.

Klatzo, I., Wisniewski, H. \& Streicher, E. (1965). Experimental production of neurofibrillary degeneration. I. Light microscopic observations. Journal of Neurobiology and Experimental Neurology 24, $187-199$.

Kowall, N. W., Beal, M. F., Busciglio, J., Duffy, L. K. \& Yankner, B. A. (1991). An in vivo model for the neurodegenerative effects of $\beta$-amyloid and protection by substance $\mathrm{P}$. Proceedings of the National Academy of Sciences USA 88, 7247-7251.

Marottta, C. A., Majocha, R. E. \& Tate, B. (1992). Molecular and cellular biology of Alzheimer amyloid. Journal of Molecular Neuroscience 3, 111-125.

O'Neill, D., Condren, L., O'Kelly, F., King, A., Young, M., Walsh, J. B. \& Coakley, D. (1988). Cognitive impairment in the elderly. Irish Medical Journal 81, 11-13.

Pike, G. J., Walencewicz, A. J., Glabe, C. G. \& Cotman, C. W. (1991). In vitro aging of $\beta$-amyloid protein causes peptide aggregation and neurotoxicity. Brain Research 563, 311-314.

Price, J. L., Davies, P. B., Morris, J. C. \& White, D. L. (1991). The distribution of tangles, plaques and related immunohistochemical markers in healthy aging and Alzheimer's disease. Neurobiology \& Aging 12, 295-312.

Quon, D., Wang, Y., Catalano, R., Marian Scardina, J., Murakami, K. \& Cordell, B. (1991). Formation of $\beta$-amyloid deposits in brains in transgenic mice. Nature 352, 239-241.

Richards, S.-J., Waters, J. J., Abraham, C., Beyreuther, K., Masters, C. L., Wischik, C. \& Dunnett, S. B. (1991). Transplants of Mourse Trisomy 16 Hippocampus Provide a Model of Alzheimer's Disease Neuropathology. Embo Journal 10, 297-303.

Royal College of Physicians (1981). Report of the Royal College of Physicians on Organic Mental Impairment in the Elderly. Journal of the Royal College of Physicians, London 15, 4-29.

Royston, M. C., Rothwell, N. J. \& Roberts, G. W. (1992). Alzheimer's disease: pathology to potential treatments? Trends in Pharmacological Sciences 13, 131-133.

Selkoe, D. J. (1991). The molecular pathology of Alzheimer's disease. Neuron 6, 487-498.

Van der Voet, G. B., Marani, E. \& de Wolff, F. A. (1991). Aluminium neurotoxicity. In Histo-and Cytochemistry as a Tool in Environmental Toxicology. Progress in Histo- and Cytochemistry, vol. 23, pp. 235-242 [W. Graumann and J. Drukker, editors]. Stuttgart: Gustav Fischer Verlag.

Van Nostrand, W. E., Wagner, S. L., Shankle, W. R., Farrow, J. S., Dick, M., Rozemuller, J. M., Kuiper, M. A., Walters, E. C., Zimmerman, J. \& Cotman, C. W. (1992). Decreased levels of soluble amyloid $\beta$-protein precursor in cerebrospinal fluid of Alzheimer disease patients. Proceedings of the National Academy of Sciences USA 89, 2551-2554.

Walton, J. (1991). Alzheimer's Disease and the Environment. Royal Society of Medicine Round Table Series no. 26. London: Royal Society of Medicine Services. 
Williams, R. J. P. (1992). Aluminium in Biology and Medicine. Ciba Foundation Symposium no. 169. Chichester: John Wiley \& Sons Ltd.

Wischik, C. M. (1991). Molecular neuropathology of Alzheimer's disease. In Carers, Professionals and Alzheimer's Disease, pp. 239-251 [D. O'Neill, editor]. London: John Libbey.

Yankner, B. A., Duffy, L. K. \& Kirschner, D. A. (1990). Neurotrophic and neurotoxic effects of amyloid B-protein: reversal by tachykinin neuropeptides. Science 250, 279-282.

Younkin, S. G. (1991). Processing of the Alzheimer's Disease BA4 Amyloid Protein Precursor (APP). Brain Pathology 1, 253-262. 